\title{
ANALISIS EFISIENSI PERBANKAN YANG TERDAFTAR DI BURSA EFEK INDONESIA (BEI) TAHUN 2012-2013
}

\author{
Oleh: \\ Dichi Febrian Putra \\ Mahasiswa Pasca Sarjana Ilmu Ekonomi Universitas Gadjah Mada \\ putrafebrian677@yahoo.com
}

\begin{abstract}
The aims of this study is to measure and explain the efficiency level of bank listed on the Indonesia Stock Exchange (IDX) 2012-2013, as well as to analyze the composition of input and output that must be performed by an inefficient banking and the best reference for an inefficient banking on efficient banking. The data analysis technique that used in this study is using Data Envelopment Analysis (DEA) by using a model of Constant Return to Scale (CRS) consisting of the input variable (deposit, fixed assets, and the cost of labor) and output (loans). The result of this study indicated that the 33 banks listed on the Stock Exchange has an average technical efficiency of $86.72 \%$ in 2012 and $84.98 \%$ in 2013. Overall only six banks that have $100 \%$ value of efficiency in 2012, while in 2013 there are five banks which have 100\% value of efficiency. Banks that have an efficiency value $100 \%$ can be a reference for a bank that has inefficient value which is under 100\%. The cause of large inefficiency is because the disbursed loan variable has a value $81.81 \%$ on 2012 and $84.84 \%$ on 2013.
\end{abstract}

Keywords: Efficiency, Data Envelopment Analysis (DEA),Banking Stock Exchange

\begin{abstract}
ABSTRAK
Tujuan dari penelitian ini adalah mengukur dan menjelaskan tingkat efisiensi perbankan yang terdaftar di bursa efek indonesia (BEI) tahun 20122013, serta menganalisis komposisi input output yang harus dilakukan oleh perbankan yang inefisien dan rujukan terbaik untuk perbankan yang inefisien pada perbankan yang efisien. Teknik analisis data yang digunakan dalam penelitian ini menggunakan Data Envelopment Analysis (DEA) dengan menggunakan model Constant Return to Scale (CRS) yang terdiri dari variabel input (simpanan, asset tetap, dan biaya tenaga kerja) dan output (kredit yang disalurkan). Hasil penelitian ini menunjukkan bahwa 33 bank yang terdaftar di BEI memiliki rata-rata efisiensi teknis sebesar 86.72\% pada tahun 2012 dan 84.98\% pada tahun 2013. Dari 33 bank hanya 6 bank yang memiliki efisiensi 100\% pada tahun 2012, sedangkan pada tahun 2013 hanya terdapat 5 bank yang memiliki efisiensi 100\%. Bank yang memiliki nilai efisiensi $100 \%$ dapat menjadi referensi bank yang kurang efisien atau memiliki nilai dibawah 100\%. Penyebab inefisiensi terbesar adalah karena variabel output kredit yang disalurkan yakni sebesar $81.81 \%$ pada tahun 2012 dan 84.84\% pada tahun 2013.
\end{abstract}

Kata Kunci: Efisiensi, Data Envelopment Analysis (DEA), Perbankan BEI 


\section{PENDAHULUAN}

Tujuan berdirinya sebuah perusahaan salah satunya adalah untuk memperoleh profit secara maksimal. Tapi dalam kenyataannya tidak semua perusahaan mampu memperoleh profit sesuai dengan tujuan semula karena profit dari perusahaan tidak hanya digunakan untuk biaya operasional perusahaan, membayar gaji karyawan, tunjangan, serta mengeluarkan biaya - biaya lain, tetapi juga digunakan untuk ekspansi perusahaan. Agar memperoleh keuntungan yang diharapkan, perusahaan perlu mengelola sumber daya yang dimiliki secara profesional. Salah satu cara mengelola perusahaan secara profesional adalah dengan melakukan efisiensi. Sebuah perusahaan dikatakan efisien apabila dapat mengelola input minimal untuk menghasilkan output yang maksimal.

Setiap perusahaan memiliki karakteristik masing-masing sehingga dalam mengelola efisiensi juga harus disesuaikan dengan karakteristik perusahaan tersebut. Apabila ditinjau dari segi produk terdapat dua macam perusahaan, yaitu perusahaan yang menjual produk berbentuk barang dan perusahaan yang menjual produk dalam bentuk jasa. Salah satu perusahaan yang bergerak dalam menjual jasa adalah perbankan atau umumnya dikenal sebagai bank. Fungsi bank sendiri adalah sebagai perantara masyarakat yang membutuhkan dana (deficit) dengan masyarakat yang kelebihan dana (surplus). Menurut Undang-Undang Perbankan Nomor 10 Tahun 1998 yang dimaksud dengan bank adalah badan usaha yang menghimpun dana dari masyarakat dalam bentuk simpanan dan menyalurkannya ke masyarakat dalam bentuk kredit dan/atau bentuk lainnya dalam rangka meningkatkan taraf hidup rakyat banyak. Dua fungsi pokok bank yaitu penghimpunan dana masyarakat dan penyaluran dana kepada masyarakat, oleh karena itu disebut Financial Intermediary (Ismail, 2011).

Masyarakat Ekonomi Asean (MEA) 2015. MEA merupakan perdagangan bebas antara anggotaanggota ASEAN. Saat ini, BOPO perbankan nasional sekitar 70-80 
persen hal ini masih tergolong tinggi apabila dibandingkan dengan bankbank di kawasan ASEAN yang BOPO-nya sudah mencapai 40-60 persen. Apabila perbankan Indonesia tidak melakukan efisiensi maka hal ini akan menimbulkan masalah dan perbankan di Indonesia akan kalah dengan perbankan di kawasan ASEAN. Tujuan dari penelitian ini adalah (1) Mengukur dan menjelaskan tingkat efisiensi perbankan yang terdaftar di bursa efek Indonesia (BEI) tahun 20122013; (2) Mengukur dan menganalisis komposisi input dan output yang harus dilakukan oleh perbankan yang inefisien dan rujukan terbaik untuk perbankan yang inefisien pada perbankan yang efisien.

\section{METODOLOGI PENELITIAN}

Teknik analisis yang digunakan dalam penelitian ini adalah analisis kuantitatif dengan menggunakan pendekatan non-parametrik Data Envelopment Analysis (DEA). Dalam penelitian ini akan menggunakan software Warwick for Data Envelopment Analysis (WDEA). Hal yang terpenting dalam menggunakan alat analisis DEA adalah dengan menentukan variabel input dan outputnya serta menentukan orientasi model yang digunakan. Dalam penelitian ini peneliti menggunakan model Constant Return to Scale (CRS). Model CRS dipilih karena belum ada hubungan tingkat efisiensi bank dengan skala produksi bank (Suseno, 2008 dalam Firdaus, 2013). Model CCR seringkali disebut dengan constant return to scale $(C R S)$, yaitu perbandingan nilai input dan output yang bersifat konstan. Hal ini berarti bahwa bank akan berada pada satu garis lurus yang memotong sumbu origin. Model CCR dapat diformulasikan sebagai berikut:

$$
\begin{array}{ll}
\sum_{j=1}^{n} x i j \lambda i j>\theta i o & i=1,2, \ldots, m \\
\sum_{j=1}^{n} y r j \lambda j \leq y i o & r=1,2, \ldots, s \\
\sum_{j=1}^{n} x j>0 & j=1,2, \ldots, n
\end{array}
$$

Dimana

$$
\begin{array}{ll}
\theta & =\text { Efisiensi DMU Model CCR } \\
\mathrm{n} & =\text { Jumlah DMU } \\
\mathrm{m} & =\text { Jumlah input } \\
\mathrm{s} & =\text { Jumlah output } \\
x i j & =\text { Jumlah input ke-i DMU j }
\end{array}
$$


$y r j \quad=$ Jumlah output ke-r DMU $\mathrm{j}$

$\lambda j=$ Bobot DMU j untuk DMU yang dihitung

Pada model CCR, tidak terdapat syarat convexity constraint, berbeda dengan model BankerCharnes-Cooper (BCC) yang terdapat syarat convexity constraint (Amalo, 2012). Nilai efisien dalam DEA berkisar antara nol sampai satu. DMU yang efisien akan memiliki nilai 1 atau $100 \%$, sedangkan nilai yang mendekati nol menunjukkan efisiensi DMU yang semakin rendah atau dianggap tidak efisien secara relatif. Pengolahan data dalam penelitian ini diperlukan variabel input dan output. Variabel input yang digunakan dalam penelitian ini adalah Jumlah simpanan $\left(\mathrm{I}_{1}\right)$, Aktiva Tetap $\left(\mathrm{I}_{2}\right)$, dan Biaya untuk Tenaga Kerja $\left(\mathrm{I}_{3}\right)$ Sedangkan variabel output dalam penelitian ini yaitu Kredit yang Disalurkan/Diberikan $\left(\mathrm{O}_{1}\right)$.

\section{HASIL PENELITIAN DAN PEMBAHASAN}

Hasil pengukuran kinerja efisiensi perbankan yang terdaftar di bursa efek Indonesia tahun 2012-
2013 ditunjukkan oleh tabel dibawah ini:

\section{Tabel 1. Kinerja Efisiensi DEA Masing - Masing Perbankan Tahun 2012- 2013}

\begin{tabular}{clrr}
\hline \multicolumn{4}{c}{ Kinerja Efisiensi Perbankan } \\
\hline No & Nama Bank & $\mathbf{2 0 1 2}$ & \multicolumn{1}{c}{$\mathbf{2 0 1 3}$} \\
\hline 1 & Mandiri & 86.14 & 85.46 \\
\hline 2 & BRI & 85.83 & 88.12 \\
\hline 3 & BCA & 70.51 & 72.55 \\
\hline 4 & BNI & 76.38 & 79.09 \\
\hline 5 & CIMB Niaga & 96.67 & 87.12 \\
\hline 6 & Danamon & 100 & 83.77 \\
\hline 7 & Pan Indonesia & 100 & 96.62 \\
\hline 8 & Permata & 100 & 93.46 \\
\hline 9 & Internasional Ind & 92.40 & 87.67 \\
\hline 10 & BTN & 100 & 100 \\
\hline 11 & OCBC NISP & 89.50 & 89.37 \\
\hline 12 & BPD Jabar\&Banten & 74.92 & 86.56 \\
\hline 13 & Bukopin & 92.41 & 84.68 \\
\hline 14 & Mega & 53.08 & 53.68 \\
\hline 15 & BTPN & 89.69 & 79.62 \\
\hline 16 & BPD Jatim & 88.90 & 83.02 \\
\hline 17 & Ekonomi Raharja & 93.99 & 92.94 \\
\hline 18 & Artha Graha Internas & 90.46 & 84.76 \\
\hline 19 & Mayapada Internas & 81.35 & 86.16 \\
\hline 20 & Mutiara & 87.06 & 83.52 \\
\hline 21 & Sinarmas & 81.13 & 74.95 \\
\hline 22 & Victoria Internas & 83.46 & 92.46 \\
\hline 23 & Nusantara Parahyang & 99.72 & 100 \\
\hline 24 & Pundi Indonesia & 78.43 & 75.47 \\
\hline 25 & Himpunan Saudara & 83.74 & 83.70 \\
\hline 26 & ICB Bumiputera & 89.73 & 100 \\
\hline 27 & Windu Kentjana Int & 80.47 & 80.12 \\
\hline 28 & Capital Indonesia & 64.62 & 67.53 \\
\hline 29 & QNB Kesawan & 86.66 & 100 \\
\hline 30 & BRI Agroniaga & 100 & 94.99 \\
\hline 31 & Bumi Arta & 77.45 & 77.18 \\
\hline 32 & India-Indonesia & 100 & 100 \\
\hline 33 & Nationalnobu & 86.97 & 59.79 \\
\hline Sumber: Data Diolah & & \\
\hline & & & \\
\hline
\end{tabular}

Perhitungan efisiensi dengan menggunakan model Constant 
Return to Scale (CRS) menghasilkan beberapa hal sebagai berikut:

1. Bank-bank yang memperoleh nilai efisien $100 \%$ pada tahun 2012 ada 6 bank yakni Bank Danamon, Bank Pan Indonesia, Bank Permata, Bank BTN, Bank BRI Agroniaga dan Bank IndiaIndonesia.

2. Pada tahun 2012 ada 27 bank yang mendapat nilai efisiensi dibawah $100 \%$ yakni Bank Mandiri (86.14\%), BRI (85.83\%), BCA $(70.51 \%)$, BNI (76,38\%), Bank CIMB Niaga (96.67\%), Bank Internasional Indonesia (92.40\%), Bank OCBC NISP (89.50\%), BPD Jabar \& Banten (74.92\%), Bank Bukopin (92.41\%), Bank Mega (53.08\%), Bank BTPN (89.69\%), Bank BPD Jatim (88.90\%), Bank Ekonomi Raharja (93.99\%), Bank Artha Graha Internasional (90.46\%), Bank Mayapada Internasional (81.35\%), Bank Mutiara (87.06\%), Bank Sinarmas (81.13\%), Bank Victoria Internasional $(83.46 \%), \quad$ Bank Nusantara Parahyangan (99.72\%), Bank Pundi Indonesia (78.43\%),
Bank Himpunan Saudara (83.74\%), Bank ICB Bumiputera (89.73\%), Bank Windu Kentjana Internasional (80.47\%), Bank Capital Indonesia (64.62\%), Bank QNB Kesawan (86.66\%), Bank Bumi Arta (77.45\%), dan Bank Nationalnobu (86.97\%).

3. Sedangkan pada tahun 2013 ada 28 bank yang mendapat nilai efisiensi dibawah $100 \%$ yakni Bank Mandiri (85.46\%), BRI (88.12\%), BCA $(72.55 \%)$, BNI (79,09\%), Bank CIMB Niaga $(87.12 \%)$, Bank Internasional Indonesia (87.67\%), Bank OCBC NISP (89.37\%), BPD Jabar \& Banten (86.56\%), Bank Bukopin (84.68\%), Bank Mega (53.68\%), Bank BTPN (79.62\%), Bank BPD Jatim (83.02\%), Bank Ekonomi Raharja (92.94\%), Bank Artha Graha Internasional (84.76\%), Bank Mayapada Internasional (86.16\%), Bank Mutiara (83.52\%), Bank Sinarmas (74.95\%), Bank Victoria Internasional (92.46\%), Bank Pundi Indonesia (75.47\%), Bank Himpunan Saudara (83.70\%), Bank Windu Kentjana 
Internasional $(80.12 \%), \quad$ Bank Capital Indonesia (67.53\%), Bank Bumi Arta (77.18\%), dan Bank Nationalnobu (59.79\%).

4. Pada tahun 2013 terdapat 5 bank yang berhasil meraih tingkat efisiensi $100 \%$. Dua bank berhasil mempertahankan tingkat efisiensi 100\% yakni Bank BTN dan Bank India-Indonesia serta 3 bank baru yang berhasil meningkatkan efisiensi menjadi $100 \%$ yakni Bank ICB Bumiputera, Bank Nusantara Parahyangan, dan Bank QNB Kesawan.
5. Empat bank mengalami penurunan tingkat efisiensi pada tahun 2013 yakni Bank Danamon, Bank Pan Indonesia, Bank Permata, dan Bank Agroniaga.

Selain dapat memperbaiki komposisi input-output perbankan yang inefisien, software DEA juga dapat memberikan rekomendasi atau bank acuan supaya bank yang kurang efisien menjadi efisien. Tabel 2 adalah tabel bank yang menjadi acuan bagi bank-bank yang kurang efisien pada tahun 2012:

Tabel 2. Bobot dan Referensi Bank Acuan Bagi Bank yang Inefisien Tahun 2012

\begin{tabular}{|c|c|c|c|}
\hline Nama Bank & Score Efisien & Bank Acuan & Bobot \\
\hline \multirow[b]{2}{*}{ Bank Mega } & \multirow{2}{*}{53.08} & Bank Danamon & 0.068 \\
\hline & & BTN & 0.548 \\
\hline \multirow{2}{*}{ Bank Capital Indonesia } & \multirow{2}{*}{64.62} & Bank Pan Indonesia & 0.038 \\
\hline & & BTN & 0.011 \\
\hline \multirow{3}{*}{ BCA } & \multirow{3}{*}{70.51} & Bank Pan Indonesia & 0.433 \\
\hline & & BTN & 2.990 \\
\hline & & Bank India-Indonesia & 42.912 \\
\hline \multirow{2}{*}{ Bank BPD Jabar\&Banten } & \multirow{2}{*}{74.92} & BTN & 0.355 \\
\hline & & Bank India-Indonesia & 9.782 \\
\hline \multirow[b]{2}{*}{ Bank BNI } & \multirow{2}{*}{76.38} & BTN & 2.654 \\
\hline & & Bank India-Indonesia & 22.086 \\
\hline \multirow{2}{*}{ Bank Bumi Arta } & \multirow{2}{*}{77.45} & Bank Danamon & 0.006 \\
\hline & & BTN & 0.029 \\
\hline Bank Pundi Indonesia & 78.43 & Bank Danamon & 0.075 \\
\hline \multirow{2}{*}{ Bank Windu Kentjana } & \multirow{2}{*}{80.47} & Bank Danamon & 0.001 \\
\hline & & BTN & 0.068 \\
\hline \multirow{2}{*}{ Bank Sinarmas } & \multirow{2}{*}{81.13} & Bank Pan Indonesia & 0.013 \\
\hline & & BTN & 0.143 \\
\hline \multirow{2}{*}{ Bank Mayapada Internasional } & \multirow{2}{*}{81.35} & Bank Pan Indonesia & 0.025 \\
\hline & & BTN & 0.156 \\
\hline \multirow{2}{*}{ Bank Victoria Internasional } & \multirow{2}{*}{83.46} & Bank Pan Indonesia & 0.089 \\
\hline & & Bank India-Indonesia & 0.498 \\
\hline
\end{tabular}




\begin{tabular}{llll}
\hline \multirow{2}{*}{ Bank Himpunan Saudara } & \multirow{2}{*}{83.74} & Bank Danamon & 0.005 \\
\cline { 3 - 4 } & & BTN & 0.072 \\
\hline
\end{tabular}

Sumber : (Laporan Keuangan, diolah dengan DEA)

Menurut tabel 2, bank acuan dengan bobot bank yang efisien untuk bank yang belum efisien yakni:

1. Pada tahun 2012 Bank Mega, Bank Bumi Arta, Bank Windu Kentjana, Bank Himpunan Saudara serta Bank QNB Kesawan (Tabel 2) dapat menjadikan Bank Danamon dan BTN sebagai acuan agar memiliki kinerja lebih efisien, artinya Bank Mega, Bank Bumi Arta, Bank Windu Kentjana, Bank Himpunan Saudara serta Bank QNB Kesawan dapat menentukan sesuai target input dan outputnya pada Bank Danamon ditambah dengan BTN Sesuai dengan bobot yang ditentukan agar menjadi lebih efisien. Adapun Bank Mega harus menargetkan input outputnya sebesar 0.068 untuk Bank Danamon dan 0.548 untuk BTN. Bank Bumi Arta menargetkan input outputnya dengan bobot 0.006 untuk Bank
Danamon dan 0.029 untuk BTN, Bank Windu Kentjana harus menargetkan input outputnya sebesar 0.001 untuk Bank Danamon dan 0.068 untuk BTN, dan Bank QNB Kesawan agar menjadi efisien menargetkan input outputnya sebesar 0.027 untuk Bank Danamon dan 0.015 untuk BTN.

2. Bank Capital Indonesia, Bank Sinarmas, dan Bank Mayapada dapat menjadikan Bank Pan Indonesia dan BTN sebagai acuan mereka dengan bobot yang sudah ditentukan. Bank Capital Indonesia dapat menjadikan Bank Pan Indonesia dan BTN dengan masing-masing bobotnya sebesar (0.038) dan (0.011), Bank Sinarmas dapat menjadikan Bank Pan Indonesia dan BTN dengan bobot masingmasing sebesar (0.013) dan (0.143), sedangkan Bank Mayapada Internasional dapat menjadikan Bank Pan Indonesia dan BTN dengan masing-masing 
bobot sebesar (0.025) dan (0.156).

3. BPD Jabar \& Banten dan BNI dapat menjadikan BTN dan Bank India-Indonesia sebagai acuan agar menjadi lebih efisien. BPD Jabar \& Banten dapat menjadikan BTN sebagai acuan dengan bobot (0.355) dan Bank India-Indonesia dengan bobot (9.782), sedangkan BNI dapat menjadikan BTN sebagai acuan dengan bobot (2.654) dan Bank India-Indonesia dengan bobot (22.086).

4. BCA dapat menjadikan 3 bank sebagai acuan untuk memperbaiki efisiensi yaitu Bank Pan Indonesia, BTN, dan Bank India-Indonesia dengan masing-masing bobot (0.433), (2.990), dan (42.912). Bank Pundi Indonesia dapat menjadikan Bank Danamon sebagai acuan dengan bobot (0.075), Bank Victoria Internasional dapat menjadikan Bank Pan Indonesia sebagai acuan dengan bobot (0.089) ditambah dengan Bank IndiaIndonesia dengan bobot (0.498).

BRI, Bank ICB Bumiputera, dan Bank Nusantara Parahyangan dapat menjadikan Bank Permata ditambah dengan BRI-Agroniaga sebagai acuan dengan masingmasing bobot (3.236) dan (36.234) untuk BRI, untuk Bank ICB Bumiputera dapat menjadikan Bank Permata dengan bobot (0.049) dan BRI Agroniaga dengan bobot (0.435), sedangkan Bank Nusantara Parahyangan dapat menjadikan Bank Permata dengan bobot (0.031) dan BRI Agroniaga dengan bobot (1.186) sebagai acuan agar menjadi lebih efisien. Data dari 3 bank ini bisa dilihat pada tabel 3 dibawah.

Tabel 3. Bobot dan Referensi Bank Acuan Bagi Bank yang Inefisien Tahun 2012

\begin{tabular}{lcrc}
\hline \multicolumn{1}{c}{ Nama Bank } & Score Efisien & Bank Acuan & Bobot \\
\hline \multirow{2}{*}{ Bank BRI } & \multirow{2}{*}{85.83} & Bank Permata & 3.236 \\
\cline { 3 - 4 } Bank Mandiri & \multirow{2}{*}{86.14} & Bank BRI Agroniaga & 36.234 \\
\cline { 3 - 4 } & \multirow{2}{*}{ Bank QNB Kesawan } & Bank India-Indonesia & 80.261 \\
\cline { 3 - 4 } & \multirow{2}{*}{86.66} & Bank Danamon & 0.027 \\
\hline
\end{tabular}




\begin{tabular}{lcrc}
\hline Bank Nationalnobu & 86.97 & BRI Agroniaga & 0.194 \\
\hline \multirow{3}{*}{ Bank Mutiara } & \multirow{2}{*}{87.06} & Bank Pan Indonesia & 0.034 \\
\cline { 2 - 3 } & & Bank BTN & 0.040 \\
\cline { 2 - 3 } & & Bank India-Indonesia & 3.455 \\
\hline Tabel 3 dilanjutkan pada pada halaman 23 &
\end{tabular}

Lanjutkan dari tabel 1 pada halaman 22

\begin{tabular}{|c|c|c|c|}
\hline \multirow{2}{*}{ Bank BPD Jatim } & \multirow{2}{*}{88.90} & Bank BTN & 0.005 \\
\hline & & Bank India-Indonesia & 11.050 \\
\hline \multirow{2}{*}{ Bank OCBC NISP } & \multirow{2}{*}{89.50} & Bank BTN & 0.299 \\
\hline & & Bank India-Indonesia & 18.594 \\
\hline \multirow[b]{2}{*}{ Bank BTPN } & \multirow[b]{2}{*}{89.69} & Bank BTN & 0.279 \\
\hline & & Bank India-Indonesia & 11.526 \\
\hline \multirow{2}{*}{ Bank ICB Bumiputera } & \multirow{2}{*}{89.73} & Bank Permata & 0.049 \\
\hline & & Bank BRI Agroniaga & 0.435 \\
\hline \multirow{2}{*}{ Bank Artha Graha } & \multirow{2}{*}{90.46} & Bank Pan Indonesia & 0.051 \\
\hline & & Bank BTN & 0.151 \\
\hline \multirow{2}{*}{ Bank Internasional-Indonesia } & \multirow{2}{*}{92.40} & Bank BTN & 0.288 \\
\hline & & Bank India-Indonesia & 31.791 \\
\hline \multirow{2}{*}{ Bank Bukopin } & \multirow{2}{*}{92.41} & Bank Pan Indonesia & 0.115 \\
\hline & & Bank India-Indonesia & 20.685 \\
\hline \multirow{2}{*}{ Bank Ekonomi Raharja } & \multirow{2}{*}{93.99} & Bank BTN & 0.060 \\
\hline & & Bank India-Indonesia & 8.170 \\
\hline \multirow{2}{*}{ Bank CIMB Niaga } & \multirow{2}{*}{96.67} & Bank BTN & 0.356 \\
\hline & & Bank India-Indonesia & 61.996 \\
\hline \multirow[t]{2}{*}{ Bank Nusantara Parahyangan } & \multirow[t]{2}{*}{99.72} & Bank Permata & 0.031 \\
\hline & & Bank BRI Agroniaga & 1.186 \\
\hline
\end{tabular}

Sumber : (Laporan Keuangan, diolah dengan DEA).

Tabel 3 diatas merupakan lanjutan dari bank acuan dengan bobot bank yang efisien untuk bank yang belum efisien. Tabel 3 menunjukkan bahwa ada 7 bank yang dapat menjadikan BTN dan Bank India-Indonesia. Bank Mandiri dapat menjadikan BTN sebagai acuan dengan bobot (3.527) ditambah dengan Bank IndiaIndonesia dengan bobot (80.261), BPD Jatim dapat menjadikan BTN sebagai acuan dengan bobot (0.005) ditambah dengan Bank IndiaIndonesia dengan bobot (11.050), Bank OCBC NISP dapat menjadikan BTN sebagai acuan dengan bobot (0.299) dan Bank India-Indonesia dengan bobot (18.594), BTPN dapat menjadikan BTN sebagai acuan dengan bobot (0.279) ditambah dengan Bank India-Indonesia dengan bobot (11.526), Bank Internasional Indonesia dapat menjadikan BTN 
sebagai acuan dengan bobot (0.288) ditambah dengan Bank IndiaIndonesia dengan bobot (31.791), Bank Ekonomi Raharja dapat menjadikan BTN sebagai acuan dengan bobot (0.060) dan Bank India-Indonesia dengan bobot (8.170), dan yang terakhir adalah Bank CIMB Niaga dapat mengacu pada BTN dengan bobot sebesar (0.356) ditambah Bank IndiaIndonesia dengan bobot sebesar (61.996).

Bank Nationalnobu dapat mengacu pada satu bank saja agar menjadi lebih efisien, yaitu pada BRI Agroniaga dengan bobot sebesar (0.194), Sedangkan Bank Mutiara dapat mengacu pada 3 bank agar menjadi efisien yaitu Bank Pan Indonesia dengan bobot (0.034), BTN dengan bobot (0.040), dan ditambah dengan Bank IndiaIndonesia dengan bobot (3.455). Bank Artha Graha dapat mengacu pada 2 bank agar lebih efisien yaitu pada Bank Pan Indonesia dengan bobot (0.051) ditambah dengan BTN dengan bobot (0.151). Bank terakhir yang dapat meningkatkan efisiensi yaitu Bank Bukopin dengan bank acuan antara lain Bank Pan Indonesia dengan bobot (0.115) ditambah dengan Bank India-Indonesia dengan bobot (20.685).

Tabel 4 berikut ini adalah Bank efisien yang menjadi acuan bank inefisien pada tahun 2013.

Tabel 4. Bobot dan Referensi Bank Acuan Bagi Bank yang Inefisien Tahun 2013

\begin{tabular}{lcrc}
\hline \multicolumn{1}{c}{ Nama Bank } & Score Efisien & Bank Acuan & Bobot \\
\hline \multirow{2}{*}{ Bank Mega } & \multirow{2}{*}{53.68} & Bank BTN & 0.397 \\
\cline { 3 - 4 } Bank Nationalnobu & \multirow{2}{*}{59.79} & Bank QNB Kesawan & 1.952 \\
\cline { 3 - 4 } & \multirow{2}{*}{ Bank Capital Indonesia } & \multirow{2}{*}{ Bank Nusantara Parahyangan } & 0.099 \\
\cline { 3 - 4 } & \multirow{2}{*}{ BCA } & Bank India Indonesia & 0.538 \\
\hline \multirow{2}{*}{ Bank Sinarmas } & \multirow{2}{*}{74.95} & Bank BTN & 0.005 \\
\hline Bank Pundi Indonesia & 75.47 & Bank India Indonesia & 1.965 \\
\hline \multirow{2}{*}{ Bank Bumi Arta } & \multirow{2}{*}{77.18} & Bank BTN & 4.253 \\
\cline { 3 - 4 } & & Bank QNB Kesawan & 0.113 \\
\hline
\end{tabular}




\begin{tabular}{lrrr}
\hline \multirow{2}{*}{ BNI } & \multirow{2}{*}{79.09} & Bank BTN & 2.318 \\
\cline { 3 - 4 } & & Bank QNB Kesawan & 9.514 \\
\hline \multirow{2}{*}{ Bank BTPN } & \multirow{2}{*}{79.62} & Bank QNB Kesawan & 6.382 \\
\cline { 2 - 3 } & & Bank India Indonesia & 2.251 \\
\hline
\end{tabular}

Tabel 3 dilanjutkan pada pada halaman 25

Lanjutkan dari tabel 1 pada halaman 24

\begin{tabular}{lcrc}
\hline \multirow{2}{*}{ Bank Windu Kentjana } & \multirow{2}{*}{80.12} & Bank BTN & 0.065 \\
\cline { 3 - 4 } BPD Jatim & \multirow{2}{*}{83.02} & Bank QNB Kesawan & 0.045 \\
\cline { 3 - 4 } & \multirow{2}{*}{ Bank Mutiara } & Bank QNB Kesawan & 1.238 \\
\hline Bank Himpunan Saudara & 83.52 & Bank India-Indonesia & 6.211 \\
\hline Bank Danamon & 83.77 & Bank BTN & 0.100 \\
\hline S & & Bank QNB Kesawan & 0.269 \\
\hline
\end{tabular}

Sumber: (Laporan Keuangan, diolah dengan DEA).

Tabel 4 merupakan hasil yang menunjukkan bank acuan yang efisien bagi bank-bank yang kurang efisien pada tahun 2013. Dari tabel diatas dapat diketahui bahwa :

1. Bank yang memiliki acuan BTN dan Bank QNB Kesawan agar lebih efisien ada 6 bank yaitu Bank Mega, Bank Sinarmas, Bank Bumi Arta, BNI, Bank Windu Kentjana, dan Bank Mutiara. Bank Mega dengan tingkat efisien 53.68 dapat mengacu pada BTN dengan bobot (0.397) ditambah dengan Bank QNB Kesawan dengan bobot (4.952). Bank Sinarmas dengan tingkat efisiensi 74.95 dapat mengacu pada BTN dengan bobot (0.113) ditambah dengan Bank QNB Kesawan dengan bobot (0.402). Bank Bumi Arta dengan tingkat efisiensi 77.18 dapat mengacu pada BTN dengan bobot (0.016) ditambah dengan Bank QNB Kesawan dengan bobot (0.249). BNI dengan efisiensi 79.09 dapat mengacu pada BTN dengan bobot (2.318) ditambah dengan Bank QNB Kesawan dengan bobot (9.514) agar menjadi lebih efisien. Bank Windu Kentjana dengan tingkat efisiensi 80.12 dapat mengacc pada BTN dengan bobot (0.065) ditambah dengan Bank QNB Kesawan dengan bobot (0.045), 
serta Bank ke enam yang dapat mengacu pada BTN dan Bank QNB Kesawan yitu Bank Mutiara dengan bobot BTN (0.100) dan Bank QNB Kesawan dengan bobot (0.269).

2. Dua Bank yang dapat mengacu pada Bank QNB Kesawan dan Bank India-Indonesia agar lebih efisien yaitu BTPN dengan efisiensi sebesar 79.62 dan BPD Jatim dengan efisiensi sebesar 83.02. BTPN dapat mengacu pada Bank QNB Kesawan dengan bobot (6.382) ditambah dengan Bank India-Indonesia dengan bobot sebesar (2.251), sedangkan BPD Jatim dapat mengacu pada Bank QNB Kesawan dengan bobot (1.238) ditambah dengan Bank IndiaIndonesia dengan bobot (6.211).

3. BCA dan Bank Himpunan Saudara dapat mengacu pada BTN agar lebih efisien. BCA dengan tingkat efisien sebesar 72.54 dapat mengacu pada BTN dengan bobot (4.253) agar menjadi lebih efisien, sama halnya dengan Bank Himpunan Saudara dengan efisiensi sebesar
83.70 yang dapat mengacu pada BTN dengan bobot (0.040) agar menjadi lebih efisien. Sedangkan Bank Pundi Indonesia dan Bank Danamon dapat mengacu pada Bank QNB Kesawan agar lebih efisien. Bank Pundi Indonesia dengan efisiensi sebesar 75.47 dapat mengacu pada Bank QNB Kesawan dengan bobot (1.059) agar lebih efisien, sama halnya dengan Bank Danamon supaya menjadi lebih efisien, maka dapat mengacu pada Bank QNB Kesawan dengan bobot (15.067).

4. Bank Nusantara Parahyangan dan Bank India-Indonesia dapat dijadikan acuan bagi Bank Nationalnobu dengan efisiensi 59.79 dengan bobot (0.099) untuk Bank Nationalnobu dan $(0,538)$ untuk Bank IndiaIndonesia agar menjadi lebih efisien. BTN dan Bank IndiaIndonesia dapat dijadikan acuan bagi Bank Capital Indonesia dengan efisiensi sebesar 67.53 dengan bobot (0.005) untuk BTN ditambah Bank IndiaIndonesia dengan bobot (1.965). 
Tabel 5. Bobot dan Referensi Bank Acuan Bagi Bank yang Inefisien Tahun 2013

\begin{tabular}{|c|c|c|c|}
\hline Nama Bank & $\begin{array}{l}\text { Score } \\
\text { Efisien }\end{array}$ & Bank Acuan & Bobot \\
\hline \multirow{2}{*}{ Bank Bukopin } & \multirow{2}{*}{84.68} & Bank BTN & 0.444 \\
\hline & & Bank India Indonesia & 4.787 \\
\hline \multirow{2}{*}{$\begin{array}{l}\text { Bank Artha Graha } \\
\text { Internasional }\end{array}$} & \multirow{2}{*}{84.76} & Bank BTN & 0.164 \\
\hline & & Bank QNB Kesawan & 0.216 \\
\hline \multirow{3}{*}{ Bank Mandiri } & \multirow{3}{*}{85.46} & Bank BTN & 4.157 \\
\hline & & Bank QNB Kesawan & 8.879 \\
\hline & & Bank India Indonesia & 16.328 \\
\hline \multirow{2}{*}{$\begin{array}{l}\text { Bank Mayapada } \\
\text { Internasional }\end{array}$} & \multirow{2}{*}{86.16} & Bank BTN & 0.120 \\
\hline & & Bank India Indonesia & 3.325 \\
\hline \multirow{3}{*}{ BPD Jabar\&Banten } & \multirow{3}{*}{86.56} & Bank BTN & 0.151 \\
\hline & & Bank QNB Kesawan & 3.948 \\
\hline & & Bank India Indonesia & 1.492 \\
\hline \multirow{3}{*}{ Bank CIMB Niaga } & \multirow{3}{*}{87.12} & Bank BTN & 0.626 \\
\hline & & Bank QNB Kesawan & 6.126 \\
\hline & & Bank India Indonesia & 21.596 \\
\hline \multirow{2}{*}{$\begin{array}{l}\text { Bank Internasional } \\
\text { Indonesia }\end{array}$} & \multirow{2}{*}{87.67} & Bank QNB Kesawan & 5.541 \\
\hline & & Bank India Indonesia & 24.484 \\
\hline \multirow{2}{*}{ BRI } & \multirow{2}{*}{88.12} & Bank QNB Kesawan & 4.709 \\
\hline & & Bank India Indonesia & 171.579 \\
\hline \multirow{3}{*}{ Bank OCBC NISP } & \multirow{3}{*}{89.37} & Bank BTN & 0.214 \\
\hline & & Bank QNB Kesawan & 2.711 \\
\hline & & Bank India Indonesia & 10.472 \\
\hline Bank Victoria Internasional & 92.40 & Bank India Indonesia & 4.703 \\
\hline \multirow[b]{2}{*}{ Bank Ekonomi Raharja } & \multirow[b]{2}{*}{92.94} & Bank QNB Kesawan & 0.679 \\
\hline & & Bank India Indonesia & 6.725 \\
\hline \multirow[b]{2}{*}{ Bank Permata } & \multirow[b]{2}{*}{93.46} & Bank QNB Kesawan & 2.013 \\
\hline & & Bank India Indonesia & 43.240 \\
\hline \multirow{2}{*}{ Bank BRI Agroniaga } & \multirow{2}{*}{94.99} & Bank Nusantara Parahyangan & 0.053 \\
\hline & & Bank India Indonesia & 1.343 \\
\hline
\end{tabular}




\begin{tabular}{lll}
\hline Bank Pan Indonesia & 96.62 & Bank India Indonesia \\
41.876
\end{tabular}

Sumber : (Laporan Keuangan, diolah dengan DEA)

Tabel 5 merupakan tabel bank yang mengalami inefisiensi dan daftar bank yang telah efisien beserta bobotnya yang menjadi referensi bank yang kurang efisien. Dari tabel diatas didapat penjelasan sebagai berikut:

1. Bank Mandiri, BPD Jabar \& Banten, Bank CIMB Niaga, dan Bank OCBC NISP dengan tingkat efisiensi masing-masing yakni $85.46,86.56,87.12$, dan 89.37 dapat menjadikan BTN, Bank QNB Kesawan, dan Bank IndiaIndonesia sebagai acuan agar lebih efisien. Bank Mandiri dapat mengacu pada BTN dengan bobot (4.157) ditambah Bank QNB Kesawan dengan bobot (8.879) dan ditambah Bank IndiaIndonesia dengan bobot (16.328). BPD Jabar\&Banten dapat menargetkan input outputnya pada BTN dengan bobot (0.151) ditambah Bank QNB Kesawan dengan bobot (3.948) dan ditambah Bank India-Indonesia dengan bobot (1.492). Bank CIMB Niaga dapat menargetkan input outputnya pada BTN dengan bobot (0.626) ditambah Bank QNB Kesawan dengan bobot (6.126) ditambah Bank IndiaIndonesia dengan bobot (21.596). Bank OCBC NISP dapat menargetkan input outputnya dengan acuan BTN dengan bobot (0.214) ditambah Bank QNB Kesawan dengan bobot (2.711) ditambah Bank India-Indonesia dengan bobot (10.472) agar menjadi lebih efisien.

2. Bank Bukopin dan Bank Mayapada Internasional dapat menargetkan input outputnya mengacu pada BTN dan Bank India-Indonesia. Bank Bukopin dapat mengacu pada BTN dengan bobot (0.444) ditambah Bank India-Indonesia dengan bobot (4.787), sedangkan Bank Mayapada Internasional dapat mengacu pada BTN dengan bobot (0.164) ditambah dengan Bank India-Indonesia dengan bobot (3.325).

3. Empat bank yang dapat menargetkan input output dengan 
bank acuan Bank QNB Kesawan dan Bank India-Indonesia yaitu Bank Internasional Indonesia dengan acuan Bank QNB Kesawan dengan bobot (5.541) ditambah dengan Bank IndiaIndonesia dengan bobot (24.484), BRI dengan acuan Bank QNB Kesawan berbobot (4.709) ditambah dengan Bank IndiaIndonesia dengan bobot (171.579), Bank Ekonomi Raharja dapat menjadi efisien dengan mengacu pada Bank QNB Kesawan dengan bobot (0.679) ditambah dengan Bank IndiaIndonesia dengan bobot (6.725), serta Bank Permata dapat menargetkan input outputnya dengan mengacu pada Bank QNB Kesawan dengan bobot (2.013) ditambah dengan Bank IndiaIndonesia dengan bobot (43.240).

4. Bank Artha Graha dapat menjadi efisien apabila menargetkan input outputnya pada BTN dengan bobot (0.164) ditambah Bank QNB Kesawan dengan bobot (0.216), Bank Victoria Internasional dapat menargetkan input outputnya sesuai dengan acuan Bank India-Indonesia dengan bobot (4.703). BRI Agroniaga dengan efisiensi sebesar 94.99 agar menjadi efisien maka dapat menargetkan input outputnya dari Bank Nusantara Parahyangan dengan bobot (0.053) ditambah dengan Bank India-Indonesia dengan bobot (1.343). Bank Pan Indonesia dapat menargetkan input outputnya pada Bank India-Indonesia dengan bobot (41.876) agar menjadi lebih efisien.

\section{KESIMPULAN}

Berdasarkan hasil dan pembahasan, maka kesimpulan dari penelitian ini adalah sebagai berikut:

1. Berdasarkan hasil perhitungan DEA dengan menggunakan model asumsi Constant Return to Scale (CRS), rata-rata efisiensi bank yang terdaftar di BEI pada tahun 2012 sebesar $86.72 \%$, sedangkan pada tahun 2013 rata-rata efisiensi menurun menjadi $84.98 \%$. Pada tahun 2012 bank yang efisien (bernilai 1 atau 100\%) sebanyak enam bank atau sebesar $18.18 \%$ dari total 33 bank. Sedangkan 
bank yang inefisien (bernilai kurang dari 1 atau dibawah 100\%) pada tahun 2012 sebanyak 27 bank atau sebesar $81.81 \%$ dari total 33 bank. Pada tahun 2013 bank yang efisien (bernilai 1 atau $100 \%$ ) menurun menjadi 5 bank atau sebesar $15.15 \%$ dari total 33 bank. Sedangkan bank yang inefisien (bernilai kurang dari 1 atau dibawah $100 \%$ ) pada tahun 2013 berjumlah 28 bank atau sebesar $84.84 \%$ dari total 33 bank. Enam bank yang memperoleh skor efisien pada tahun 2012 antara lain: Bank Danamon, Bank Pan Indonesia, Bank Permata, BTN, BRI Agroniaga, dan Bank India-Indonesia. Bank yang memperoleh nilai efisien pada tahun 2013 adalah BTN, Bank Nusantara Parahyangan, Bank ICB Bumiputera, Bank QNB Kesawan, dan Bank IndiaIndonesia.

2. Sumber-sumber inefisiensi teknis perbankan yang terdaftar di BEI tahun 2012-2013 berasal dari variabel input dan output.

- Bank yang mengalami inefisiensi input simpanan pada tahun 2012 sebesar 6.06\%, terdapat pada 2 bank yaitu Bank Victoria Internasional, dan Bank Nationalnobu. Pada tahun 2013 bank yang mengalami inefisiensi input simpanan sebesar $12.12 \%$ terdapat pada Bank Nationalnobu, BCA, Bank Victoria Internasional, dan Bank Pan Indonesia.

- Bank yang mengalami inefisensi asset tetap pada tahun 2012 berjumlah 10 bank, 30.30\% dari total 33 bank. Sepuluh bank tersebut antara lain: Bank Mega, Bank Capital Indonesia, Bank Bumi Arta, Bank Pundi Indonesia, Bank Windu Kentjana, Bank Sinarmas, Bank Mayapada Internasional, Bank Himpunan Saudara, Bank QNB Kesawan, dan Bank Artha Graha. Pada tahun 2013 inefisiensi asset tetap terdapat pada 16 bank atau $48.48 \%$ dari total 33 bank. Enam belas tersebut antara lain: Bank Mega, Bank Capital Indonesia, BCA, Bank Sinarmas, Bank Pundi Indonesia, Bank Bumi Arta, BNI, Bank Windu Kentjana, 
Bank Mutiara, Bank Himpunan Saudara, Bank Danamon, Bank Bukopin, Bank Artha Graha Internasional, Bank Mayapada Internasional, Bank Victoria Internasional, dan Bank Pan Indonesia.

- Inefisiensi biaya tenaga kerja pada tahun 2012 terdapat pada 14 bank atau sebesar $42.42 \%$ dari total 33 bank. Bank yang inefisiensi biaya tenaga kerja antara lain: BPD Jabar \& Banten, BNI, Bank Pundi Indonesia, BRI, Bank Mandiri, Bank Nationalnobu, BPD Jatim, Bank OCBC NISP, BTPN, Bank ICB Bumiputera, Bank Internasional Indonesia, Bank Ekonomi Raharja, Bank CIMB Niaga, dan Bank Nusantara Parahyangan. Pada tahun 2013 terdapat 10 bank atau sebesar $30.30 \%$ yang inefisien karena biaya tenaga kerja. Bank tersebut antara lain: Bank BCA, Bank Pundi Indonesia, BTPN, BPD Jatim, Bank Danamon, Bank Internasional Indonesia, BRI, Bank Ekonomi Raharja, bank Permata, dan BRI Agroniaga.

- Inefisiensi variabel output kredit yang disalurkan terdapat pada semua bank yang inefisien yakni berjumlah 27 bank atau $81.81 \%$ pada tahun 2012. Sedangkan pada tahun 2013 inefisiensi yang disebabkan oleh kredit yang disalurkan terdapat pada 28 bank atau sebesar $84.84 \%$.

\section{DAFTAR PUSTAKA}

Abidin, Zaenal, dan Endri. 2009. Kinerja Efisiensi Teknis Bank Pembangunan Daerah: Pendekatan Data Envelopment Analysis (DEA). Jurnal Akuntansi Dan Keuangan. Vol. 11, No. 1, pp. 21-29.

Amalo, Fitriningsih. 2012. Analisis Efisiensi Teknis Dan Skala Ekonomi Pada Industri Perbankan Syariah Di Indonesia. Universitas Muhammadiyah Malang. Malang.

Arafat, Wilson. 2006. Manajemen Perbankan Indonesia Teori dan Implementasi. Jakarta: Pustaka LP3ES Indonesia. 
Analisis Efisiensi Perbankan Yang Terdaftar Di Bursa Efek....Dichi Febrian Putra

Farrell, M. J. 1957. The Measurement of Productive Efficiency. Journal of the Royal Statistical Society. Series A (General). Vol. 120, No. 3, pp. 253-290.

Hidayati, Juliza. 2005. Analisis Efisiensi Bank Dengan DEA. Jurnal Sistem Teknik Industri. Vol. 6, No. 2 hal. 17-23.

Huri, M, D., Susilowati, I. 2004. Pengukuran Efisiensi Relatif Emiten Perbankan Dengan Metode Data Envelopment Analysis (DEA). Dinamika Pembangunan. Vol. 1 No. 2, hal, 96-110.

Hoque, R, and Rayhan, I. 2012. Data

Envelopment Analysis of Banking Sector In Bangladesh. Russian Journal of Agricultural and Socio-Economic Sciences. Vol. 5, No. 5, pp. 17-22.

Ismail. 2011. Perbankan Syariah. Jakarta: Kencana Prenada Media Group.

Karimzadeh, M. 2012. Efficiency

Analysis By Using Data

Envelop Analysis Model:

Evidence From India Banks.

International Journal of Latest
Trends in Finance \& Economic Sciense. Vol. 2, No. 3, pp. 228237.

Kasmir. 2012. Manajemen Perbankan: Edisi Revisi. Jakarta: PT Raja Grafindo Persada, Rajawali Pers.

Kusmargiani, Ida, S. 2006. Analisis

Efisiensi Operasional dan Efisiensi Profitabilitas Pada Bank Yang Merger Dan Akuisisi Di Indonesia (Studi Pada Bank Setelah Rekapitulasi Dan Restrukturisasi tahun 19992002). Universitas Diponegoro. Semarang.

Maflachatun. 2010. Analisis Efisiensi Teknik Perbankan Syariah Di Indonesia Dengan Metode Data Envelopment Analysis (DEA) (Studi Pada 11 Bank Syariah Tahun 2005-2008). Universitas Diponegoro. Semarang.

Mahardian, Pandu. 2008.Analisis Pengaruh Rasio CAR,BOPO, NPL, NIM Dan LDR Terhadap Kinerja Keuangan Perbankan (Studi Kasus Perusahaan Perbankan yang Tercatat di 
Analisis Efisiensi Perbankan Yang Terdaftar Di Bursa Efek....Dichi Febrian Putra

BEJ periode Juni 2002-Juni 2007). Universitas Diponegoro.

Semarang.

Prasetyo, D. 2010. Analisis Efisiensi

Teknis Dan Alokatif Hotel Di

Kawasan

Wisata

Tawangmangu Kabupaten

Karanganyar

Dengan

Menggunakan Metode DEA

(Data Envelopment Analysis).

Universitas Sebelas Maret.

Surakarta.

Qurniawati, R. S. 2013. Efisiensi

Perbankan Di Indonesia Dan

Pengaruhnya Terhadap Return

Saham Dengan Pendekatan

Data envelopmen Analysis

(DEA). BENEFIT Jurnal

Manajemen dan Bisnis. Vol.

17, No 1, pp. 27-40.

Solikah, Y, U. 2010. Analisis

Efisiensi Koperasi Pegawai

Negeri Republik Indonesia Di

Kabupaten Klaten. Universitas

Sebelas Maret. Surakarta.

Statistik Perbankan Indonesia. 2013.

Vol. 12 No. 1. http://bi.go.id.

Diakses tanggal 26 September 2014.

Sutawijaya, A., Lestari, E, P. 2009.

Efisiensi Teknik Perbankan
Indonesia

Pascakrisis

Ekonomi: Sebuah Studi

Empiris Penerapan Model

DEA. Jurnal Ekonomi

Pembangunan. Vol. 10. No. 1, hal, 49-67.

Thagunna, K, S., and Poudel, S. 2013. Measuring Bank Performance of Nepali Banks: A Data Envelopment Analysis (DEA) Perspective.

International Journal of Economics and Financial Issues. Vol. 3, No. 1, pp. 5465.

Wijayanto, A., Sutarno. 2010.

Kinerja Efisiensi Fungsi

Intermediasi Bank Persero Di

Indonesia

Dengan

Menggunakan

Data

Envelopment Analysis (DEA).

Jurnal Keuangan dan

Perbankan. Vol. 14. No. 1, hal. 110-121.

Zamorano, Luis, R. M. 2004.

Economic Efficiency and

Frontier Techniques. Journal

Of Economic Surveys. Vol. 18, No. 1, pp. 33-77.

https://id.berita.yahoo.com/efisiensi-

perbankan-kunci-hadapi- 
Analisis Efisiensi Perbankan Yang Terdaftar Di Bursa Efek....Dichi Febrian Putra

persaingan-mea-2015-

133017430--finance.html.

diakses tanggal 29 September 2014. www.stabilitas.co.id.

2012.

Perbankan Nasional Tak

Cukup Besar. Diakses 28

September 2014. 